\title{
The Effect of Ambivalence Online Review on Consumer Purchasing Intention
}

\author{
Yanyan Wu, Ding Pan \\ School of Management, Jinan University, Guangzhou, China \\ Email:13247341608@163.com
}

How to cite this paper: Wu, Y. Y., \& Pan, D. (2017). The Effect of Ambivalence Online Review on Consumer Purchasing Intention. Psychology, 8, 848-861. https://doi.org/10.4236/psych.2017.86055

Received: March 15, 2017

Accepted: April 27, 2017

Published: April 30, 2017

Copyright $\odot 2017$ by authors and Scientific Research Publishing Inc. This work is licensed under the Creative Commons Attribution International License (CC BY 4.0).

http://creativecommons.org/licenses/by/4.0/ (c) (i) Open Access

\begin{abstract}
Online review has been playing an important role in consumer decision making and enterprise marketing recently. This study focuses on two important issues. Firstly, how the ambivalence online review change consumer decision-making and purchase intension from the point view of different types of ambivalence online review. Secondly, how consumer of different involvement degree interprets the ambivalence online review of consumer decision. Finally, the following conclusions are obtained through the empirical study: 1) When the review about product functional attribute is positive, inter-attribute ambivalence is more significant for consumer's purchasing intension, compared with intra-attribute ambivalence. When the review about product hedonic attribute is positive, intra-attribute ambivalence is more significant to consumer's purchasing intension, compared with inter-attribute ambivalence. 2) The degree of consumer involvement has a moderating effect on the relationship between product attributes and type of ambivalence and consumer purchasing intention. When the review about product functional attribute is positive, inter-attribute ambivalence is more significant to consumer's purchasing intension, compared with intra-attribute ambivalence of high level of consumer involvement. In contrast, intra-attribute ambivalence is more significant to consumer's purchasing intension, compared with inter-attribute ambivalence for high level of consumer involvement. When the review about product enjoyment attribute is positive, intra-attribute ambivalence is more significant in consumer's purchasing intension, compared with inter-attribute ambivalence of high low of consumer involvement, thus there are no different between intra-attribute ambivalence and inter-attribute ambivalence for low level of consumer involvement.
\end{abstract}

\section{Keywords}

Ambivalence Online Review, Consumer Purchasing Intention, Product Attributes, Consumer Involvement 


\section{Introduction}

Online review has been playing an important role in consumer decision-making and enterprise marketing recently. However, due to a variety of online review information, there is positive evaluation of the product but also the negative evaluation of the product. So, facing the contradictory external information, considering consumer groups processing different methods, how consumer make decisions in that context? This has become a matter of concern.

Studies of online review have been done from different perspectives. On the one hand, the impact of online reviews on consumer decision-making and product attitudes has been studied, such as consumer opinion, user experience, product reviews. On the other hand, online review influence consumer purchasing intention and sales performance in different situations, such as product type, product price, commenter identity, product characteristics, product involvement, cultural background, relationship strength, brand strength, site type and reputation. Most of studies have analyzed the contents of the online commentary, and constructed the model to measure the influence of the information elements of the network commentary on the sales volume. Although the research on the online review has been very rich, the content of the comment and its ambivalence are still scarce.

Therefore, this paper will study the content of ambivalence online review on the impact of consumer purchase decisions, introduce the consumer involvement, and study deeply the differences between consumer groups' attitudes. It will provide a theoretical basis to network marketing activities, which will have theoretical and practical significance.

\section{Theoretical Framework}

\subsection{The Influence of Online Reviews}

Review valence. The review valence represents the bias of the online review, and also reflects the perceived quality of product. There are three major trends in review valence: positive, negative, and neutral (Purnawirawan, 2016). The positive online review and negative online review may influence consumer trust on merchant, purchase intentions, purchase behavior, and merchant sales. The positive and negative online review directly reflect the attitude of reviewer to the product, and encourage or discourage other consumer purchases, and have a more direct impact on the potential purchasers' decisions for new products. Furthermore, negative online reviews have a stronger impact on brand evaluation (Brown \& Reingen, 1987), and the potential buyers' purchase intentions (Arndt, 1967; Mizerski 1982; Richins 1983; Wright 1974).

Review volume. Review volume refers to the total number of comments and the number of different types such as the number of positive, neutral and negative online review. The greater the number, the more people buy, the more people willing to pay for the product. Studies have shown that the number of online reviews is a key driver of product sales. In fact, most studies have confirmed 
that the number of online reviews a positive impact on consumer buying intentions and sales revenue (Duan, Gu, \& Whinston, 2008; Filieri, 2014).

Review content. Review content refers to the text or image form information except the scoring, It can be divided into objective factual online review and subjective evaluation online review (Holbrook, 1978). Review content have a positive effect on sales and perceived usefulness, and the effect of subjective evaluation of online review is more significant impact on consumer decision making. Review content can influence consumer purchase intention, the more subjective of online review, the more strongly of consumer purchase intention (Jin, 2007). When consumer browsing a large number of online review, they most likely from the memory to obtain specific and distinctive subjective word of mouth information. The information is more likely to attract the attention of information seekers and long-term memory, thus influencing consumer decision-making processes (Herry, 1991).

\subsection{Product Attributes}

Product attributes refers to the product of all explicit and contains a combination of various characteristics, but can be perceived by consumers. Consumers in the consumer decision-making process will regard the product attributes as the assessment criteria for different products to evaluate, and then form a different brand attitude, and ultimately affect their purchase decision-making behavior. The existing research on the product attributes mainly start from two angles: First, consumers of different attributes of the product to determine the weight, this judgment occurred before the purchase behavior; the second is the product of different attributes and the relationship between consumer behavior research. This study focuses on the impact of different attributes on consumer purchasing intentions. Voss, Spangenberg, \& Grohmann (2003) study with functional attributes and enjoyment attributes to summarize the product attributes, functional attributes mainly refers to the product to bring consumers the basic functions and uses; enjoy ability of products refers to the product passed to the consumer Experience, fun or symbolic meaning. Consumers choose products based on both functional and enjoyable (Dhar, 2000), who often make judgments based on their performance in both areas.

\subsection{Involvement}

The concept of involvement is proposed by Hupfer and Gardner (1971), who argue that involvement refers to a certain degree of interest and interest in the individual, regardless of their particular position. Mitchell (1999) points out that an intrinsic state variable involved in representing an individual that reflects the perception, interest, or motivations triggered by a particular stimulus and context, which in turn affects consumer behavior. The degree of involvement is as follows: 1) Involvement is the degree of participation of consumers, directly affect the behavior of consumers; 2) the process involved involves the process of consumer information processing, which can be inferred that the degree of in- 
volvement of the consumer acceptance of advertising, brand awareness and consumer purchasing behavior has a significant impact; 3) The degree of involvement of the consumer has a significant impact on the consumer's acceptance, brand perception and consumer buying behavior. Therefore, the level of involvement is not only affected by the product's attributes, brands and other factors, but also by the consumer's own characteristics, the degree of consumer's subjective participation and the impact of consumer performance.

\subsection{Hypothesis}

1) the impact of product attributes and contradictory types on consumer purchasing intentions

Consumers' willingness to buy is determined by the internal and external clues of the product. When making each purchase decision, consumers are in order to get their own needs to meet their own needs, so the product's internal clues will directly affect the consumer's willingness to buy (Bhat \& Reddy, 1998). Online reviews as a typical product external clues have a significant impact on consumer purchasing intentions. Ambivalence online reviews also provide positive reviews and negative reviews of products, and consumers tend to believe that it is more objective and true than just referring to product positive or negative evaluation (Kamins \& Assael, 1987) and more likely to the commentator is based on his own real experience.

Based on the above, we propose the following assumptions:

H1: Product attributes and ambivalence types of online review have a significant impact on consumer purchasing intentions;

Product attributes include functional attributes and enjoyability attributes, in fact, consumer choose products are usually based on the product in these two aspects of the performance of its judgments (Mano \& Oliver 1993). Batra (1990) argue that consumers are primarily concerned with both the satisfaction of the product itself and the emotional satisfaction of the product before making a purchase decision. When the functional properties of the product are prominent, the consumer is seeking the satisfaction of the product itself, when the product of the enjoyment of the property is prominent, the consumer is seeking emotional satisfaction. Functional attributes are generally considered objective, credible, positive functional attributes for the product in front of consumers to establish an objective positive image, consumers expect to find a choice of a whole product in good, then they will also consider the product functional and enjoyment of satisfaction. Compared with the negative enjoyment evaluation, because the functional evaluation has a lot of objectivity evaluation, the positive functional attribute image has been deeply rooted, the negative function (view contradiction) evaluation of the role played by relatively small, and negative (Attribute contradiction) to break the consumer want to get functional and enjoyment of the overall satisfaction expectations, resulting in consumer disappointment, the consumer's willingness to buy more significant, based on this, we 
propose the following assumptions:

H1a: When functional conditions are positive, compared to ambivalence in intra-attributes, the ambivalence in inter-attributes to consumers willing to buy more;

Consumers make buying decisions about products that highlight the enjoyment of attributes, and are hoping to find emotional satisfaction (Kevoss, 2003). When enjoyment online review is negative, consumers do not seek to expect the feelings and disappointment, then affect the consumer's purchase decision. In contrast to this, since the consumer has no functional high expectations, the impact of negative functional online reviews is not as strong as the impact of negative enjoyment attributes.

Based on this, we propose the following assumptions:

H1b: When enjoyment conditions are positive, compared to the ambivalence in inter-attributes, the ambivalence in intra-attributes has a more significant impact on the purchase.

2) the moderation of consumer's involvement degree on the relationship between product attributes, contradictory types and consumer purchasing intentions.

Consumer involvement has a certain impact on brand loyalty and purchase attitude as a regulatory variable. Oliva (1993) pointed out that the consumers with higher degree of involvement will start the central path, and they can find a best brand for them in that context more likely. In contrast, in the purchase process, the lower the degree of involvement of the buyer, it will start the edge of the path, they are more likely to purchase the process as a try or because it is not important and tend to occur brand transformation phenomenon. We also believe that different degree of involvement of consumers in the face of contradictory information, will make different purchase decisions. When there is a contradictory online commentary, the high degree of involvement of the consumer information processing level is higher, because consumers through the fine processing to form a comprehensive evaluation of the product or brand. At this point, the high degree of involvement of consumers will invest a lot of time and energy on the product. When the positive functional attributes are commented, consumers are expected to be able to make a full satisfaction with the product selection, subject to a negative impact (attribute contradiction) on the negative impact of online reviews that will produce expected dissatisfaction and have an impact on the purchase intention. When the positive enjoyment attribute reviews are positive, consumers are expected to be able to get emotional satisfaction, subject to negative enjoyment (view contradiction) the negative impact of online comments, will produce expectations of dissatisfaction, affecting consumer decision-making. For low-profile consumers, when faced with a large number of online commentary information, they will start the edge of the path, in the enjoyment of the positive situation, the low degree of involvement of consumers will not invest a lot of energy in the product Information on the search, conflicting contradictory information will greatly combat their continued 
interest in browsing, therefore, compared to the contradictions of the property, when there are contradictions, their purchase intention will be more affected.

Therefore, we propose the following assumptions:

$\mathrm{H} 2$ : the degree of consumer involvement on the product attributes and contradictory types of consumer purchasing intentions have a regulatory role;

$\mathrm{H} 2 \mathrm{a}$ : When the functional attributes are positive, the impact of the contradiction of the property on the purchase intention of the consumer is more significant than that of the high degree of involvement. For the low participation degree consumers, Compared with the contradiction of the property, the contradiction between the view and the purchase intention of the consumer is more significant;

$\mathrm{H} 2 \mathrm{~b}$ : Under the circumstances of enjoyment attributes is positive, the high degree of involvement of consumers, compared to the contradictions of the property, the contradiction between the views of consumers to buy more significant impact on the low involvement of consumers, Compared with the contradiction between the view, the contradiction between the property and the purchasing intention of the consumer is more significant;

The research model of this paper is shown in the following figure, see Figure 1.

\section{Experiment 1}

The purpose of Experiment 1 is to verify the impact of product attributes and contradictory types on consumer purchasing intentions.

\subsection{Design and Process}

Experiment 1 uses 2 (functional attribute is positive: enjoyment attribute is positive) $* 2$ (inter-attribute ambivalence: intra-attribute ambivalence) between the group factor design. We invited 150 students from Jinan University to participate in this experiment. The valid sample was 131 after eliminating the 19 subjects who did not complete the experiment according to the experimental instructions. Among them, men accounted for $44.3 \%$, women accounted for $55.7 \%$. $63.4 \%$ of undergraduates and $36.6 \%$ of postgraduates. There was no significant effect on demographic information variables such as age and gender, and follow-up statistical analysis did not take into account.

Subjects were randomly assigned to one of the four experimental groups after they entered the laboratory. The experiment uses the scene simulation method.

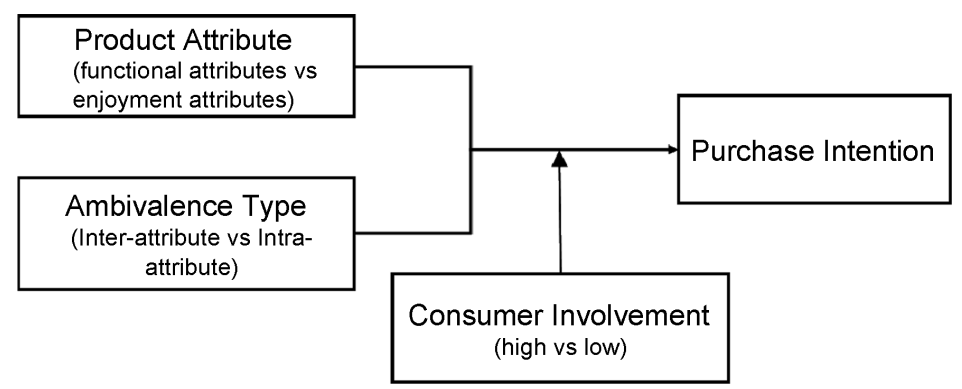

Figure 1. The ambivalence of online review on consumer purchasing intention. 
Ask the subjects to read the material carefully and think of themselves as one of the customers. After the experiment began, we painted a scene for the subjects to browse the product and view the review. Specific steps are as follows: 1) in this experiment, to the subjects described the purchase of mobile life scenes, and contact their own life reality. 2) Through the manipulation of the type of contradiction to stimulate the consumer's willingness to buy changes. 3) After the scenario hypothesis stimulus, the subjects were asked to evaluate the degree of involvement of the consumer and the willingness to buy. The degree of consumer involvement comes from the Zaichkowsky (1985) research scale, a total of 10 items. Finally, the subjects asked to answer the question of manipulation test, which included the perception that the functionality was positive or positive.

\subsection{Variable Measurement}

The scale of purchase intention is the Baker and Churchill (1977) development of the purchase intention of the mature scale, a total of four items, as shown in the following table, see Table 1 .

We manipulate the type of contradiction by designing different commentary titles and product attributes of the review content. In the online review group that embodies the contradiction of the attribute, including the functionality is positive and the negative and the function is negative, the music is positive; in the online review group which embodies the contradiction of the view, the function is positive and enjoyment for the pleasure of being negative.

\subsection{Result}

For consumer intention, The Cronbach's $\alpha$ coefficient is greater than 0.8 and has good reliability and the KMO is 0.831 , greater than 0.7 , with good validity.

According to the experimental results, we found that: the purchase intention as the dependent variable, product attributes and contradictory types as independent variables, 2 (product attributes: functional is positive vs. enjoyment is positive) ${ }^{\star} 2$ (contradictory type: inter-attribute ambivalence vs. intra-attribute ambivalence) analysis of variance.

The results show that the main effect of the product attribute is significant, $\mathrm{F}$ $(1130)=4.804, P=0.030<0.05$, the main effect of the contradictory type is not significant, $\mathrm{F}(1130)=0.600, P=0.440$, product attribute and contradictory type interaction Significant, F $(1130)=20.135, P=0.000$, see Table 2.

Therefore, $\mathrm{H} 1$ is established.

Table 1. Measurement of purchase intention.

\begin{tabular}{lc}
\hline \multicolumn{1}{c}{ Measure the item } & Source of the item \\
\cline { 2 - 3 } I think this phone is very good & Baker and \\
I love this phone very much & Churchill (1977) \\
I am willing to take the initiative to search the phone in the online mall & \\
I am very likely to buy this phone
\end{tabular}


According to the results, we can see that when the function is positive, the purchase intention of the attribute contradiction $(M=4.031)$ is significantly higher than the purchase intention $(\mathrm{M}=3.235), P=0.010$; when the enjoyment is positive, $(M=3.727)$ when the purchase intention is significantly higher than the property contradiction $(\mathrm{M}=2.598)$ when the purchase intention, $P=0.000$. In other words, in the case where the enjoyment of the product online commentary is positive, the negative enjoyment commentary is more likely to be purchased by the consumer than the negative functional reviews, and when the functionality of the product online review is positive, Negative functional reviews on the negative enjoyment of the reviews on the consumer's purchase will be greater. Therefore, H1a is satisfied, it is assumed that H1b is established.

\subsection{Discussion}

1) When the functional is positive, there are significant differences in the effect of different types of contradictions on the purchase intention of consumers. The contradiction of attribute ( $\mathrm{M}$ attribute contradiction $=4.031$ ) is more significant than that of viewpoint ( $M$ view contradiction $=3.235$ ). In other words, in the case of functional positive, relatively negative functional online comments, negative enjoyment online comment more able to affect the consumer's willingness to buy, see Figure 2.

Table 2. Statistics of product attributes * ambivalence types.

\begin{tabular}{lccccc}
\hline \multicolumn{4}{c}{ Dependent variable: purchase intention } \\
\hline \multirow{2}{*}{$\begin{array}{c}\text { Product Attributes } \\
\text { Functional is positive }\end{array}$} & Ambivalence types & Mean & Standard error & 95\% confidence interval \\
& Intra-attribute ambivalence & 4.031 & 0.217 & 3.602 & 4.461 \\
& Inter-attribute ambivalence & 3.235 & 0.214 & 2.812 & 3.658 \\
& Intra-attribute ambivalence & 2.598 & 0.214 & 2.176 & 3.021 \\
Enjoyment is positive & Inter-attribute ambivalence & 3.727 & 0.214 & 3.304 & 4.150 \\
\hline
\end{tabular}

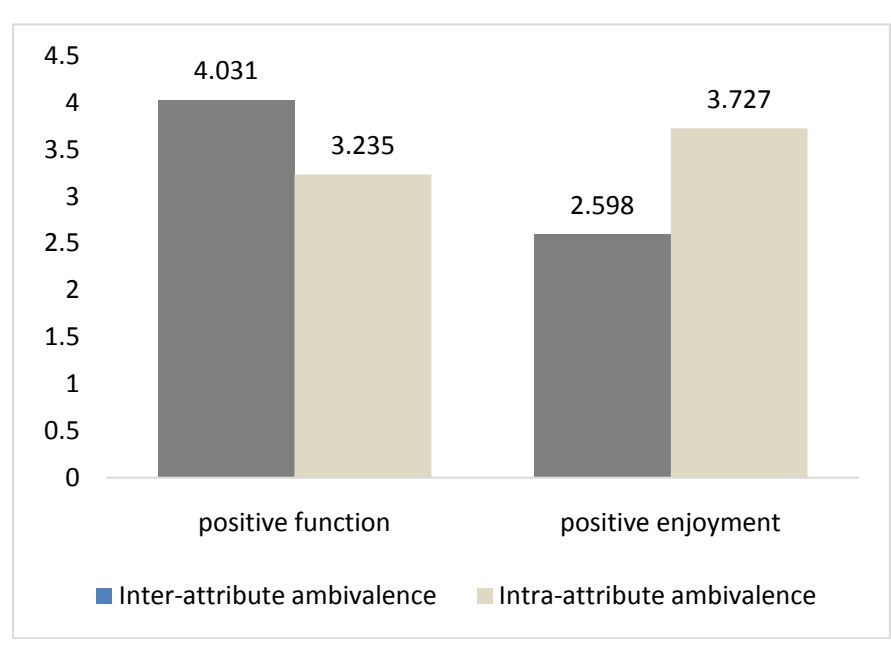

Figure 2. Impact of different types of contradictions on consumer purchasing intentions. 
2) When the enjoyment is positive, there are significant differences in the effect of different types of contradictions on the purchase intention of consumers, and the contradiction of view ( $\mathrm{M}$ view contradiction $=3.727$ ) is more significant than the attribute contradiction ( $\mathrm{M}$ attribute contradiction $=2.598$ ), see Figure 2.

\section{Experiment 2}

The purpose of Experiment 2 is to verify the role of consumer involvement in the relationship between product attributes and contradictory types in the impression of consumer purchasing intension.

\section{Design and Process}

Experiment 2 uses 2 (product attribute: positive function vs positive enjoyment) * 2 (contradiction type: inter-attribute ambivalence vs intra-attribute ambivalence) ${ }^{*} 2$ (consumer involvement degree: high degree of involvement vs low involvement degree) Intergroup factor design. We invited 210 students to participate in this experiment. After excluding 19 subjects who did not complete the experiment, there were 191 valid questionnaires, including 93 males, $48.6 \%$ and $51.3 \%$ of girls. 116 undergraduates, accounting for $60.7 \%$, 75 graduate students, accounting for $39.2 \%$.

After the subjects entered the laboratory, they were randomly assigned to one of the eight experimental groups. The experiment uses the scene simulation method. Ask the subjects to read the material carefully and think of themselves as their customers. After the experiment began, the subjects described a scene browsing the product and browsing the comments. Specific steps are as follows: 1) in this experiment, to the subjects described the purchase of mobile life scenes, and contact their own life reality. 2) Through the manipulation of the type of contradiction to stimulate the consumer's willingness to buy changes. 3) After the scenario hypothesis stimulus, the subjects were asked to evaluate the degree of involvement of the consumer and the willingness to buy. The degree of consumer involvement comes from the Zaichkowsky (1985) research scale, a total of 10 items. Finally, the subjects asked to answer the question of manipulation test, which included the perception that the functionality was positive or positive.

\subsection{Result}

For Consumer Involvement, the Cronbach's alpha coefficient is 0.775 and the $\mathrm{KMO}$ is 0.767. For Consumer Purchase Intention, the Cronbach's alpha coefficient is 0.919 and the $\mathrm{KMO}$ is 0.831 , indicating that the scale has acceptable reliability and validity.

The results show that the main effect of consumer involvement is not significant, $\mathrm{F}(1183)=2.59, P=0.109$; the main effect of product attributes is not significant, $\mathrm{F}(1183)=3.754, P=0.054$, the main effect of contradictory type $(1183)=$ $0.182, P=0.076$; consumer interaction, product attributes and contradictory types of triple interaction significantly, $\mathrm{F}(1183)=21.853, P=0.000$.

Therefore, assume $\mathrm{H} 2$ is true. 
As the triple interaction is significant, the next simple and simple effect analysis will be carried out.

In the case of positive functionality, when the degree of human involvement is high, the impact of the attribute contradiction on the purchase intention is significantly higher than the impact of the view on the purchase intention, $M$ attribute $=4.324, \mathrm{M}$ view $=3.261, P=0.000$ When the degree of consumer involvement is low, the influence of opinion contradiction on purchase intention is significantly higher than the influence of attribute contradiction on purchase intention, $\mathrm{M}$ attribute $=3.154, \mathrm{M}$ view $=5.000, P=0.014$;

In the case of positive enjoyment, when the degree of consumer involvement is high, the influence of opinion contradiction on purchase intention is significantly higher than the impact of property contradiction on purchase intention, $\mathrm{M}$ attribute $=2.440, \mathrm{M}$ view $=3.899, \mathrm{P}=0.000$; When the consumer involvement is low, the type of contradiction has no significant effect on the purchase intention, $\mathrm{M}$ attribute $=3.917, \mathrm{M}$ view $=3.500, P=0.482$.

\subsection{Discussion}

Through the above analysis, the following conclusions are drawn:

The degree of consumer involvement has a moderating effect on the relationship between contradictory types, product attributes and willingness to buy. in particular:

In the context of functionalism, the impact of the contradiction of the attribute $(\mathrm{M}=4.324)$ is more significant than that of the view $(\mathrm{M}$ view $=3.261)$ for the high degree of involvement; for the low involvement For example, the contradiction of opinion $(\mathrm{M}$ attribute $=3.154)$ is more significant than the property contradiction $(\mathrm{M}$ view $=5.000)$ on consumer purchasing intention, see Figure 3. In the case of high enjoyment, the contradiction of opinion contradiction $(\mathrm{M}$ view $=3.899)$ is more significant than that of attribute $(\mathrm{M}$ attribute $=$ 2.440) for consumers' willingness to buy, and for low involvement ( $P=0.482)$, the contradiction between the contradiction between the attribute and the opinion is not significant $(P=0.482)$, see Figure 4 .

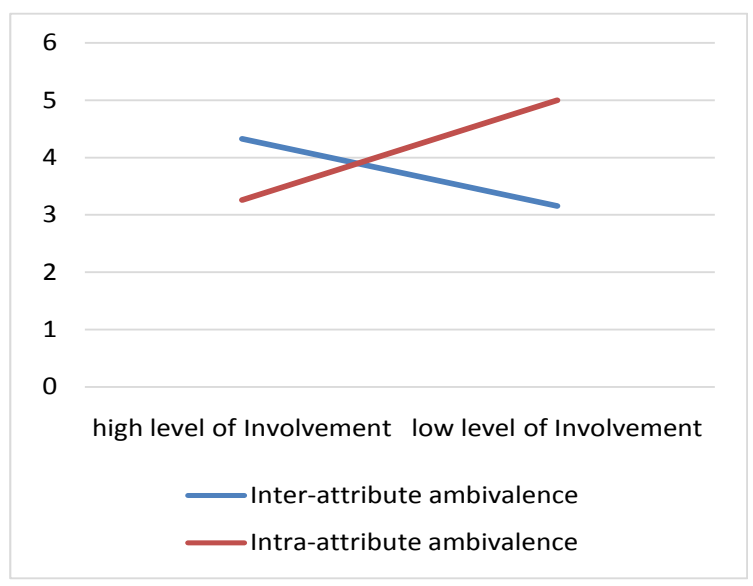

Figure 3. The score of consumer purchase intention with positive function. 


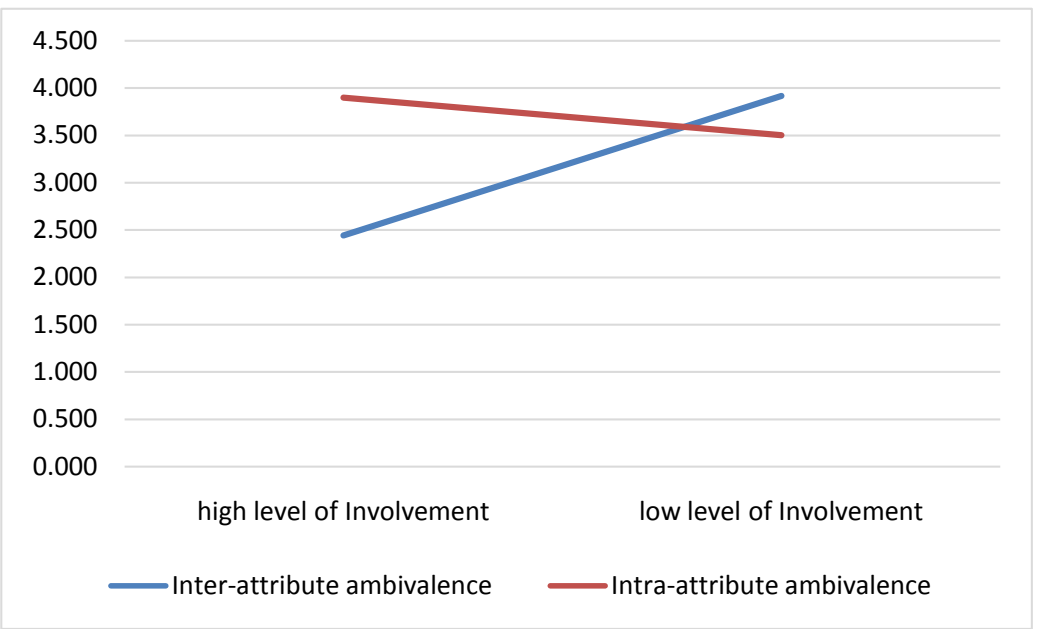

Figure 4. The score of consumer purchase intention with positive enjoyment.

\section{General Discussion}

Online review is an important source of information that affects consumers' online shopping decisions and is increasingly concerned by practitioners and academics. At present, there are many theories on online review, but few studies considerate the impact of online criticism on consumer purchasing intentions. Compared to the previous study, this paper has made the following contributions:

First of all, this paper focuses on the possible impact of the contradiction of online commentary on the purchase intention of consumers, and explores the differences of consumers' individual in the online shopping environment in different contradictory situations. The results of the study have enriched the research on the content of online commentary, and the future research of marketing-related issues provides a new entry point.

Second, different from the previous study to explore the contradiction of online commentary will be judged positive and negative proportion is divided into equal circumstances, ignoring the positive and negative proportion of comments is the key to forming a contradictory online comment. This study explores the differences in the contradictory psychology of consumers in situations where the tendency of tendencies is coexisting in the context of the dominant tendency. And from the combination of product attributes and contradictory types of research, it tries to explain the cross between the two effects for the future online commentary research, which provides a new direction.

According to the conclusion of this paper, the practice of enterprise network marketing has the following inspiration:

1) Pay attention to the management of online reviews. Online shopping as an important shopping channel for consumers, in the face of fierce competitive environment, businesses want to get greater market share and consumer loyalty, we must attach great importance to customers online reviews, especially negative comments, recognizing that online reviews are an important source of information for consumer shopping decisions that directly affect consumer decision 
making. The specific strategies that can be taken are as follows: i) For the high degree of involvement of consumers, under the premise of maintaining the positive product attribute tendency, the enterprise should pay more attention to the maintenance of the attribute review, satisfy the consumers' "Pleasure is very good" is expected. ii) For consumers with low involvement, in the face of the contradiction between functional attributes, enterprises should emphasize the functional attributes of products in order to alleviate the negative impact of negative function evaluation on low-involvement consumers. iii) For functional products or comments in the functional evaluation of positive products, to encourage consumers to express more enjoyable comments to help potential consumers to establish the product "overall good" image. iv) For the enjoyment of the product or comment on the evaluation of the positive side of the product, to encourage consumers to express more positive comments, to prevent negative feedback on the release to help consumers get in line with the expected product reviews.

2) Negative comments prevention. Negative comments are more persuasive than positive online reviews on potential consumers, and negative comments should be avoided from the following: i) Pre-purchase precautions before the purchase to fully inform the function of consumer products and the possible emotional pleasure, to avoid fraud. ii) Negative comments should be dealt with in a timely manner, with special emphasis on the enjoyment of the enjoyment of attributes, whether functional or enjoyable products, when there are negative comments, the enjoyment of comments will cause a greater impact.

3) Different degrees of involvement of consumers. Businesses should promptly respond to consumer online consultation and consumers to actively communicate to understand the causes of consumer sentiment to maintain immediate online communication, for different consumers to take different measures. In general, for the high degree of involvement of consumers, whether functional products or enjoy the type of products, we should pay attention to the enjoyment of the attributes of cognitive correction; for low involvement of consumers, when dealing with functional products, attention should be paid to the positive image construction of functional attributes.

\section{References}

Arndt, J. (1967). Role of Product-Related Conversations in the Diffusion of a New Product. Journal of Marketing Research, 4, 291-295. https://doi.org/10.2307/3149462

Baker, M. J., \& Churchill, G. A. (1977). The Impact of Physically Attractive Models on Advertising Evaluations. Journal of Marketing Research, 14, 538-555. https://doi.org/10.2307/3151194

Batra, S. K., Ghosh, T. K., \& Barker, R. L. (1990). The Bending Behaviour of Plain-Woven Fabrics Part III: The Case of Bilinear Thread-Bending Behaviour and the Effect of Fabric Set. Journal of the Textile Institute, 81, 272-287. https://doi.org/10.1080/00405009008658710

Bhat, S., \& Reddy, S. K. (1998). Symbolic and Functional Positioning of Brands. Journal 
of Consumer Marketing, 15, 32-43.

https://doi.org/10.1108/07363769810202664

Brown, J. J., \& Reingen, P. H. (1987). Social Ties and Word-of-Mouth Referral Behavior. Journal of Consumer Research, 14, 350-362. https://doi.org/10.1086/209118

Dhar, R., \& Wertenbroch, K. (2000). Consumer Choice between Hedonic and Utilitarian Goods. Journal of Marketing Research, 37, 60-71. https://doi.org/10.1509/jmkr.37.1.60.18718

Duan, W., Gu, B., \& Whinston, A. B. (2008). Do Online Reviews Matter?-An Empirical Investigation of Panel Data. Decision Support Systems, 45, 1007-1016.

Filieri, R. (2014). What Makes Online Reviews Helpful? A Diagnosticity Adoption Framework to Explain Information and Normative Influences in E-WOM. Journal of Business Research, 68, 1261-1270.

Herry, P. M., Kardes, F. R., \& Kim, J. (1991). Effects of Word-of-Mouth and Product-Attribute Information on Persuasion: An Accessibility Diagnosticity Perspective. Journal of Consumer Research, 17, 454-462. https://doi.org/10.1086/208570

Holbrook, M. B. (1978). Beyond Attitude Structure: Toward the Informational Determinants of Attitude. Journal of Marketing Research, 15, 545-556. https://doi.org/10.2307/3150624

Hupfer, N. T., \& Gardner, D. M. (1971). Differential Involvement with Products and Issues: An Exploratory Study (pp. 262-270). Duluth, MN: Association for Consumer Research.

Jin, L. (2007). Determinants of Customer's Complaint Intention: Model and Empirical Analysis Based on China's Retail Trade. Nankai Business Review, 10, 38-46.

Kamins, M. A., \& Assael, H. (1987). Two-Sided versus One-Sided Appeals: A Cognitive Perspective on Argumentation, Source Derogation, and the Effect of Disconfirming Trial on Belief Change. Journal of Marketing Research, 24, 29-39.

https://doi.org/10.2307/3151751

Kevoss, B. G. (2003). Measuring the Hedonic and Utilitarian Dimensions of Consumer Attitude. Journal of Marketing Research, 40, 310-320.

https://doi.org/10.1509/jmkr.40.3.310.19238

Mano, H., \& Oliver, R. L. (1993). Assessing the Dimensionality and Structure of the Consumption Experience: Evaluation, Feeling and Satisfaction. Journal of Consumer Research, 20, 451-466. https://doi.org/10.1086/209361

Mitchell, V. M. (1999). Consumer Perceived Risk: Conceptualizations and Models. European Journal of Marketing, 33, 163-195. https://doi.org/10.1108/03090569910249229

Mizerski, R. W. (1982). An Attribution of the Disproportionate Influence of Unfavorable Information. Journal of Consumer Research, 9, 301-310.

https://doi.org/10.1086/208925

Oliva, T. A., \& Oliver, R. L. (1993). The Relationships among Consumer Satisfaction, Involvement and Product Performance. Behavioral Science, 40, 104-110. https://doi.org/10.1002/bs.3830400203

Purnawirawan, N., Pelsmacker, P. D., \& Dens, N. (2016). Balance and Sequence in Online Reviews: How Perceived Usefulness Affects Attitudes and Intentions. Journal of Interactive Marketing, 26, 244-255.

Reinstein, D. A., \& Snyder, C. M. (2005). The Influence of Expert Reviews on Consumer Demand for Experience Goods: A Case Study of Movie Critics. The Journal of Industrial Economics, 53, 27-51.

Richins, M. L., \& Bloch, P. H. (1983). An Investigation of Cognitive Structure in a Shopping Context. Advances in Consumer Research, 10, 555. 
Voss, K. E., Spangenberg, E. R., \& Grohmann, B. (2003). Measuring the Hedonic and Utilitarian Dimensions of Consumer Attitude. Journal of Marketing Research, 40, 310-320. https://doi.org/10.1509/jmkr.40.3.310.19238

Wright, P. (1974). The Harassed Decision Maker: Time Pressures, Distractions, and the Use of Evidence. Journal of Applied Psychology, 59, 555-561. https://doi.org/10.1037/h0037186

Zaichkowsky, J. L. (1985). Measuring the Involvement Construct. Journal of Consumer Research, 12, 341-352. https://doi.org/10.1086/208520

Submit or recommend next manuscript to SCIRP and we will provide best service for you:

Accepting pre-submission inquiries through Email, Facebook, LinkedIn, Twitter, etc. A wide selection of journals (inclusive of 9 subjects, more than 200 journals) Providing 24-hour high-quality service User-friendly online submission system Fair and swift peer-review system Efficient typesetting and proofreading procedure Display of the result of downloads and visits, as well as the number of cited articles Maximum dissemination of your research work

Submit your manuscript at: http://papersubmission.scirp.org/ Or contact psych@scirp.org 